\title{
Outcomes of Ahmed glaucoma valve implantation in advanced primary congenital glaucoma with previous surgical failure
}

This article was published in the following Dove Press journal:

Clinical Ophthalmology

3 June 2015

Number of times this article has been viewed

\author{
Jingjing Huang' \\ Jialiu Lin' \\ Ziqiang $\mathrm{Wu}^{2}$ \\ Hongzhi $\mathrm{Xu}^{3}$ \\ Chengguo Zuo' \\ Jian $\mathrm{Ge}^{1}$
}

'State Key Laboratory of Ophthalmology, Department of Glaucoma, Zhongshan Ophthalmic Center, Sun Yat-sen University, Guangzhou, People's Republic of China; ${ }^{2}$ Center for Advanced Eye Care, Carson City, NV, USA; ${ }^{3}$ Institute of Child Health Policy, University of Florida, Gainesville, FL, USA
Correspondence: Jingjing Huang State Key Laboratory of Ophthalmology, Department of Glaucoma, Zhongshan Ophthalmic Center, Sun Yat-sen University, 54 Xianlienan Road, Guangzhou 510060, People's Republic of China

Tel +862087331545

Fax +86208733 327I

Email hjjing@mail.sysu.edu.cn
Purpose: The purpose of this study was to evaluate the intermediate surgical results of Ahmed glaucoma valve (AGV) implantation in patients less than 7 years of age, with advanced primary congenital glaucoma who have failed previous surgeries.

Patients and methods: Consecutive patients with advanced primary congenital glaucoma that failed previous operations and had undergone subsequent AGV implantation were evaluated retrospectively. Surgical success was defined as 1) intraocular pressure (IOP) $\geq 6$ and $\leq 21 \mathrm{mmHg}$; 2) IOP reduction of at least $30 \%$ relative to preoperative values; and 3 ) without the need for additional surgical intervention for IOP control, loss of light perception, or serious complications.

Results: Fourteen eyes of eleven patients were studied. Preoperatively, the average axial length was $27.71 \pm 1.52(25.56-30.80) \mathrm{mm}$, corneal diameter was $14.71 \pm 1.07(13.0-16.0) \mathrm{mm}$, cup-todisc ratio was $0.95 \pm 0.04(0.9-1.0)$, and IOP was $39.5 \pm 5.7(30-55) \mathrm{mmHg}$. The mean follow-up time was $18.29 \pm 10.96$ (5-44, median 18) months. There were significant reductions in IOPs and the number of glaucoma medications $(P<0.001)$ postoperatively. The IOPs after operation were $11.3 \pm 3.4,13.6 \pm 5.1,16.3 \pm 2.7$, and $16.1 \pm 2.6 \mathrm{mmHg}$ at 1 month, 6 months, 12 months, and 18 months, respectively. Kaplan-Meier estimates of the cumulative probability of valve success were $85.7 \%, 71.4 \%$, and $71.4 \%$ at 6,12 , and 18 months, respectively. Severe surgical complications, including erosion of tube, endophthalmitis, retinal detachment, choroidal detachment, and delayed suprachoroidal hemorrhage, occurred in $28.6 \%$ cases.

Conclusion: AGV implantation remains a viable option for patients with advanced primary congenital glaucoma unresponsive to previous surgical intervention, despite a relatively high incidence of severe surgical complications.

Keywords: primary congenital glaucoma, Ahmed glaucoma valve, surgical complication

\section{Introduction}

Primary congenital glaucoma is one of the most important causes of childhood blindness in the world despite its rarity. ${ }^{1,2}$ Trabeculotomy has achieved long-term success in most cases of congenital glaucoma, ${ }^{3,4}$ but the success rate is low in advanced or latepresenting cases. ${ }^{5}$ Combined trabeculotomy-trabeculectomy procedures may improve outcomes. ${ }^{5,6}$ Dietlein et $\mathrm{al}^{7}$ suggested that the prognosis of ab externo glaucoma surgery was governed more by individual course and severity of disease than surgical technique. However, even in the best of hands, up to $15 \%-30 \%$ of primary surgeries failed. ${ }^{3-6}$ The use of intraoperative mitomycin $\mathrm{C}$ (MMC) improved the survival of trabeculectomy blebs, ${ }^{8,9}$ but it is associated with a high incidence of bleb-related infections. ${ }^{9}$

In the recent decades, Ahmed glaucoma valves (AGVs) have been implanted in patients with pediatric glaucoma. ${ }^{10,11}$ It demonstrated slight superiority compared to 
trabeculectomy ${ }^{12,13}$ and a success rate similar to other valve implants. ${ }^{10}$ In the current study, we present the outcomes of AGV implantation in patients less than 7 years old with extremely advanced primary congenital glaucoma that have failed previous surgeries.

\section{Patients and methods}

\section{Patient recruitment}

In this retrospective study, patients were recruited from September 2009 to September 2012 at the glaucoma service of the Zhongshan Ophthalmic Center of Sun Yat-sen University (Guangzhou, China). In this center, Ahmed valves have been implanted in pediatric patients for 10 years since before the above study. All patients were younger than 7 years old, with advanced primary congenital glaucoma refractory to previous medical and surgical intervention. The diagnoses of primary congenital glaucoma were carefully made based on the history of the children, the family history, and the ocular examinations, including slit-lamp examination, gonioscopy, and fundus examinations. The study was conducted in accordance with the tenets of the Declaration of Helsinki and was approved by the Institutional Review Board. Informed consent was obtained from all the patients' legal guardians.

The recruited patients were implanted with the AGV (Model FP-8 or FP-7, New World Medical Inc., Rancho Cucamonga, CA, USA) because of increased intraocular pressure (IOP) (>25 mmHg) with enlargement of optic cup/ disc ratio and/or elongation of axial length beyond the growth of eyeball, which was not responding sufficiently to previous operations and medical therapy. All surgeries were performed by the same surgeon (JG). Exclusion criteria included other types of primary and secondary pediatric glaucoma; previous intraocular surgery, except antiglaucoma surgery; eyes with leukoma, preventing observation of the anterior chamber; and eyes requiring simultaneous combined surgeries (eg, penetrating keratoplasty, cataract extraction, etc).

\section{Examinations and follow-up}

Before surgery, all patients underwent detailed ocular examination that included best-corrected visual acuity (BCVA), slit-lamp examination, gonioscopy, stereoscopic ocular fundus examination with an indirect or slit-lamp lens, IOP measurement by Goldmann applanation tonometry under topical anesthesia with tetracaine eye drops if the patient was cooperative, or by Tono-pen tonometer (Tono-pen, Reichert technologies, Depew, NY, USA) under sedation with 10\% chloral hydrate $(0.5-0.7 \mathrm{~mL} / \mathrm{kg})$. Preoperative data collected included demographic information, initial diagnosis, BCVA, IOP, horizontal corneal diameter (HCD), cup-to-disc (C/D) ratio, slit-lamp examination, the number of antiglaucoma medications used before surgery, the number and type of previous ocular surgeries, and history of other ocular or systemic diseases. Postoperative data collected during the follow-up period included BCVA, IOP, slit-lamp examination, the number of antiglaucoma medications, duration of follow-up, and surgical complications. Patients were examined postoperatively at 1 week, 2 weeks, 1 month, 3 months, and then every 3 months for the first year and every 6 months thereafter. All IOPs were measured by Goldmann applanation tonometry or Tono-pen. Antiglaucoma medications were added as needed to achieve desired IOP $(<21 \mathrm{mmHg}$ without enlargement of $\mathrm{C} / \mathrm{D}$ ratio and/or HCD).

Surgical success at the last follow-up was defined as 1) IOP $\geq 6$ or $\leq 21 \mathrm{mmHg}$, and IOP reduction of at least $30 \%$ relative to preoperative values; 2 ) without the signs of the surgical failure as the following. Surgical failure at the last follow-up was defined as 1 ) IOP $<6$ or $>21 \mathrm{mmHg}$ despite medical interventions, with demand of additional surgical intervention for IOP control; 2) loss of light perception; 3) serious complications such as erosion of tube, retinal detachment, suprachoroidal hemorrhage, or endophthalmitis. During the follow-up period, eyes that needed further glaucoma surgery (including cyclophotocoagulation), needed removal of the implant, or experienced complete loss of light perception were defined as failures and marked as the end of follow-up.

\section{Surgical procedures}

The surgical procedure of AGV implantation was performed in accordance with standard documented techniques ${ }^{10,11}$ with minor modifications. Briefly, a fornix-based conjunctival flap was created in the superior temporal or inferior temporal quadrant. After priming AGV, the plate was inserted between adjacent rectus muscles under Tenon's capsule. The anterior edge of the plate was secured with 6-0 silk sutures to the sclera, 8-10 $\mathrm{mm}$ posterior to the limbus. After penetrating the limbus with a 23-gauge needle, the tube was inserted 2 $\mathrm{mm}$ deep into the anterior chamber, parallel to the iris. The anterior chamber was re-formed with viscoelastic reagent (sodium hyaluronate injection, Bausch \& Lomb Freda Pharmaceutical Corp. Ltd, Jinan, People's Republic of China) injected through a temporal paracentesis. Donor sclera was used to cover the exposed sclera tract entrance and secured with 10-0 nylon sutures. The conjunctiva was closed with 8-0 Vicryl sutures. 


\section{Statistical analysis}

Demographic data were calculated as mean \pm standard deviation. Preoperative and postoperative IOPs and medications were compared using repeated-measure analysis of variance tests. Glaucoma cumulative survival rate was calculated using Kaplan-Meier survival analysis. Statistical significance was defined as $P<0.05$.

\section{Results}

Fourteen eyes of eleven patients (seven males, four females) were included in the study. The preoperative clinical features are shown in Table 1. There were six right eyes and eight left eyes. The average age of the patients was $4.29 \pm 1.88$ (1.1-6.5) years old. The average axial length was $27.71 \pm 1.52$ (25.56-30.80) mm, corneal diameter was $14.71 \pm 1.07$ (13.0 $16.0) \mathrm{mm}, \mathrm{C} / \mathrm{D}$ ratio was $0.95 \pm 0.04$ (0.9-1.0), and IOP was $39.5 \pm 5.7(30-55) \mathrm{mmHg}$. The average number of previous glaucoma surgeries was $1.36 \pm 0.63(1-3)$.

The mean follow-up time was 18.29 10.96 (5-44, median 18) months. The cases with follow-up time shorter than 15 month were all because of the failure of the surgery. The mean IOPs before operation and during the follow-up period are shown in Figure 1. The postoperative IOPs were significantly lower than preoperative IOPs at all time points $(P<0.001)$. The IOPs were $11.3 \pm 3.4,13.6 \pm 5.1,16.3 \pm 2.7$, and $16.1 \pm 2.6 \mathrm{mmHg}$ at 1 month, 6 months, 12 months, and 18 months postoperatively. In addition, the mean number of glaucoma medications after operation decreased significantly (Figure 2) $(P<0.001)$. The mean number of glaucoma medications after operation were $0,0.43 \pm 0.65,1.10 \pm 1.10$, and $1.11 \pm 1.17$ at 1 month, 6 months, 12 months, and 18 months, respectively. However, postoperative BCVAs in two eyes were worse at last visit, while those in other eyes remained stable (Table 2). The main causes of visual loss were severe surgical complications such as retinal detachment, choroidal detachment, and delayed choroidal hemorrhage (Table 2).

The Kaplan-Meier survival analyses of the success rate are shown in Figure 3. The success rates were 85.7\%, 71.4\%, and $71.4 \%$ at 6,12 , and 18 months, respectively. Postoperative complications included shallow anterior chamber in two eyes (14.3\%), which resolved spontaneously within 5 days; tube malposition in one eye (7.1\%); erosion of tube through conjunctiva in two eyes (14.3\%), one of which resulted in endophthalmitis (7.1\%); retinal detachment and choroidal detachment in one eye (7.1\%); and delayed suprachoroidal hemorrhage $(\mathrm{DSCH})$ in one eye $(7.1 \%)$. Among the five failed cases, four ended with severe surgical complications, and one case persisted with uncontrollable IOP (Table 2). There were no cases of persistent corneal edema or cataract formation during the follow-up period.

\section{Discussion}

Expansion of the globe in children is a reflection of high IOP and optic nerve injury. ${ }^{14-16}$ Therefore, besides IOP and C/D

Table I Preoperative clinical features of the recruited patients

\begin{tabular}{|c|c|c|c|c|c|c|c|c|c|c|}
\hline Case no & Sex & $\begin{array}{l}\text { Age } \\
\text { (year) }\end{array}$ & Eye & $\begin{array}{l}\text { Times of previous } \\
\text { surgeries }\end{array}$ & Previous surgical procedures & BCVA & $\begin{array}{l}\text { IOP } \\
(\mathrm{mmHg})\end{array}$ & $\begin{array}{l}\text { Axial length } \\
(\mathrm{mm})\end{array}$ & $\begin{array}{l}\text { HCD } \\
(\mathrm{mm})\end{array}$ & C/D \\
\hline I & M & 6.5 & $\mathrm{~L}$ & 1 & Trabeculectomy & 0.02 & 55 & 27.56 & 13 & 1.0 \\
\hline \multirow[t]{3}{*}{2} & $\mathrm{~F}$ & 5.4 & $\mathrm{~L}$ & 3 & Trabeculotomy & 0.05 & 40 & 27.63 & 15 & 0.95 \\
\hline & & & & & Trabeculectomy & & & & & \\
\hline & & & & & Trabeculectomy + MMC & & & & & \\
\hline 3 & M & I.I & $\mathrm{R}$ & 1 & Trabeculotomy + Trabeculectomy & FO & 40 & 30.80 & 16 & $*$ \\
\hline \multirow[t]{2}{*}{4} & M & 5.7 & $\mathrm{~L}$ & 2 & Trabeculotomy & 0.1 & 35 & 25.56 & 14 & 0.9 \\
\hline & & & & & Trabeculectomy + MMC & & & & & \\
\hline \multirow[t]{2}{*}{5} & M & 3 & $\mathrm{R}$ & 2 & Trabeculotomy & 0.06 & 38 & 28.40 & 15.5 & 0.9 \\
\hline & & & & & Trabeculectomy & & & & & \\
\hline \multirow[t]{2}{*}{6} & $\mathrm{~F}$ & 3.5 & $\mathrm{~L}$ & 1 & Trabeculotomy + Trabeculectomy & FC & 36 & 29.32 & 15 & 1.0 \\
\hline & & 3.6 & $\mathrm{R}$ & 1 & Trabeculotomy + Trabeculectomy & $\mathrm{FC}$ & 39 & 29.26 & 15.5 & 1.0 \\
\hline \multirow[t]{3}{*}{7} & M & 5.8 & $\mathrm{R}$ & 2 & Trabeculotomy + Trabeculectomy & FC & 40 & 26.37 & 15.5 & 0.95 \\
\hline & & & & & Trabeculectomy + MMC & & & & & \\
\hline & & & $\mathrm{L}$ & 1 & Trabeculotomy + Trabeculectomy & 0.01 & 35 & 26.11 & 15 & 0.95 \\
\hline 8 & M & 3.4 & $\mathrm{~L}$ & I & Trabeculotomy + Trabeculectomy & HM & 38 & 29.21 & 16 & $*$ \\
\hline \multirow[t]{2}{*}{9} & $\mathrm{~F}$ & 6.2 & $\mathrm{R}$ & I & Trabeculectomy & 0.1 & 40 & 26.47 & 13 & 0.95 \\
\hline & & & $\mathrm{L}$ & I & Trabeculectomy & 0.2 & 45 & 26.16 & 13 & 0.9 \\
\hline 10 & $\mathrm{~F}$ & 1.2 & $\mathrm{R}$ & I & Trabeculotomy + Trabeculectomy & FO & 30 & 27.53 & 14.5 & $*$ \\
\hline II & M & 2.7 & $\mathrm{~L}$ & I & Trabeculotomy + Trabeculectomy & $\mathrm{FF}$ & 42 & 27.60 & 15 & 1.0 \\
\hline
\end{tabular}

Note: *Couldn't be seen because of corneal opacity.

Abbreviations: BCVA, best-corrected visual acuity; IOP, intraocular pressure; HCD, horizontal corneal diameter; F, female; M, male; L, left; R, right; MMC, mitomycin C; C/D, cup to disc; FO, follow object; FC, finger count; HM, hand motion; FF, fixate and follow. 


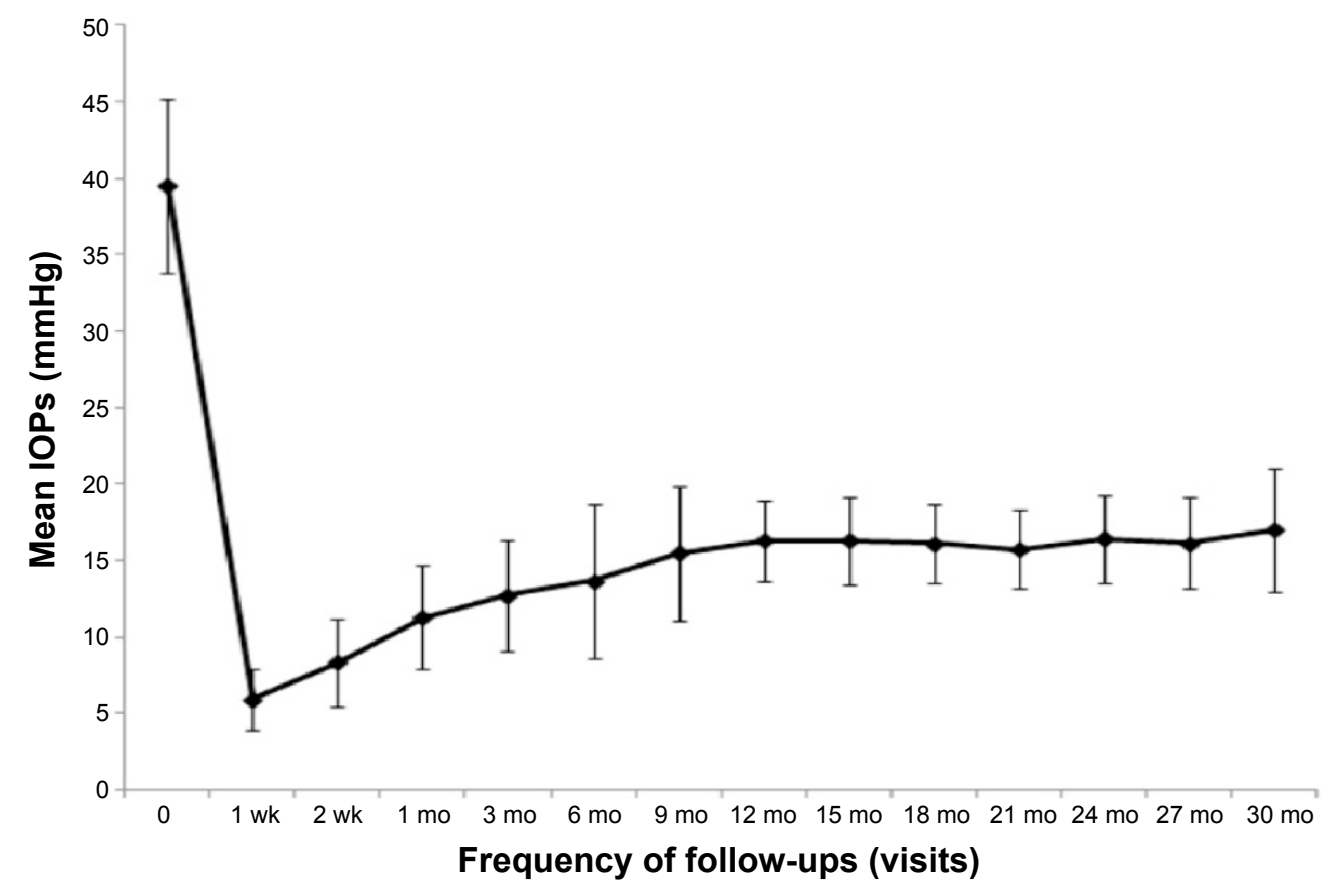

Figure I The mean intraocular pressures (IOPs) before operation and during the follow-up period.

Notes: The mean IOPs before the operation and during the follow-up period revealed that the postoperative IOPs were significantly lower than preoperative IOPs at all time points $(P<0.001)$. Error bar: I.96 standard deviations.

Abbreviations: wk, week; mo, month.

ratio, corneal diameter and axial length are deemed to be important indicators of the severity of congenital/pediatric glaucoma. ${ }^{5,14-17}$ These parameters in the current study are among the highest documented in literature, ${ }^{7,17-23}$ which reflects more advanced and long-standing disease in our cohort. Unfortunately, delayed diagnosis and advanced disease at presentation are common in developing countries. ${ }^{18}$

In this retrospective study, there were reductions in IOPs and the number of glaucoma medications following AGV implantation, with stable BCVAs in most eyes. However,

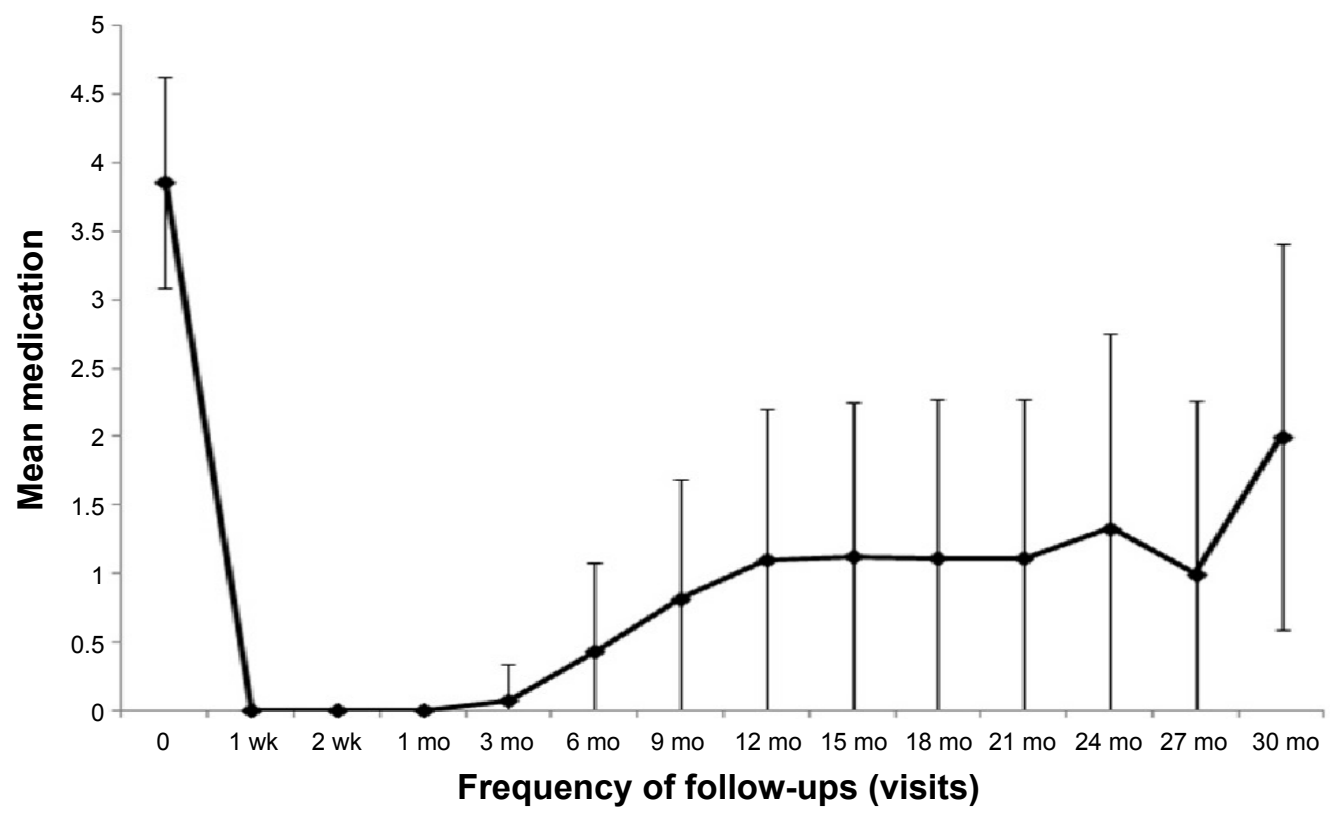

Figure $\mathbf{2}$ The mean number of glaucoma medications before operation and during the follow-up period.

Notes: The mean number of glaucoma medications before operation and during the follow-up period revealed that the patients needed less glaucoma medications after operation $(P<0.00$ I $)$. Error bar: I.96 standard deviations.

Abbreviations: wk, week; mo, month. 
Table 2 Outcome of AGV implant in the recruited patients

\begin{tabular}{|c|c|c|c|c|c|}
\hline Case no & Eye & $\begin{array}{l}\text { Follow-up } \\
\text { time (months) }\end{array}$ & $\begin{array}{l}\text { BCVA at } \\
\text { last visit }\end{array}$ & End result & $\begin{array}{l}\text { Time of fail } \\
\text { (months) }\end{array}$ \\
\hline $\mathrm{I}$ & L & 36 & 0.02 & IOP $26 \mathrm{mmHg}$ with three medications & 36 \\
\hline 2 & $\mathrm{~L}$ & 53 & 0.08 & IOP $20 \mathrm{mmHg}$ with three medications & l \\
\hline 3 & $\mathrm{R}$ & 31 & FO & Spontaneous delayed suprachoroidal hemorrahge & 31 \\
\hline 4 & L & 31 & 0.1 & IOP $17 \mathrm{mmHg}$ with one medication & l \\
\hline 5 & $\mathrm{R}$ & 9 & 0.05 & $\begin{array}{l}\text { Erosion of tube after trauma, removal of the tube, } \\
\text { transscleral laser cyclophotoablation }\end{array}$ & 9 \\
\hline \multirow[t]{2}{*}{6} & $\mathrm{~L}$ & 29 & $\mathrm{FC}$ & $\begin{array}{l}\text { Corneal attachment of the tube, IOP II mmHg } \\
\text { without medications }\end{array}$ & l \\
\hline & $\mathrm{R}$ & 6 & LP & Retinal detachment, choroidal detachment & 6 \\
\hline \multirow[t]{2}{*}{7} & $\mathrm{R}$ & 5 & $\mathrm{FC}$ & Endophthalmitis, erosion of tube, removal of the tube & 5 \\
\hline & $\mathrm{L}$ & 27 & 0.01 & IOP I $4 \mathrm{mmHg}$ without medications & 1 \\
\hline 8 & $\mathrm{~L}$ & 7 & NLP & Delayed suprachoroidal hemorrahge after trauma & 7 \\
\hline \multirow[t]{2}{*}{9} & $\mathrm{R}$ & 27 & 0.08 & IOP $19 \mathrm{mmHg}$ with two medications & I \\
\hline & $\mathrm{L}$ & 27 & 0.2 & IOP $16 \mathrm{mmHg}$ without medications & 1 \\
\hline 10 & $\mathrm{R}$ & 25 & $\mathrm{FO}$ & IOP $16 \mathrm{mmHg}$ without medications & 1 \\
\hline II & $\mathrm{L}$ & 24 & $\mathrm{FF}$ & IOP $16 \mathrm{mmHg}$ with one medication & 1 \\
\hline
\end{tabular}

Note: / = success during the follow up period.

Abbreviations: AGV, Ahmed glaucoma valve; BCVA, best-corrected visual acuity; L, left; R, right; IOP, Intraocular pressure; FO, Follow object; FC, finger count; LP, light perception; NLP, no light perception; FF, fixate and follow.

a relatively high incidence (28.6\%) of severe surgical complications was also observed.

The surgical success rate negatively correlated with severity of congenital glaucoma and depended on the type of surgery. ${ }^{5}$ Ben-Zion et $\mathrm{al}^{18}$ reported the surgical results of a group of extremely advanced primary congenital glaucoma patients (mean IOP, $54 \mathrm{mmHg}$; HCD, $15.1 \mathrm{~mm}$; C/D ratio, 0.8) in rural Ethiopia. Only 17 out of 40 eyes ended with IOP $\leq 22$ $\mathrm{mmHg}$ without severe surgical complications in the mean 6-month follow-up period (1-11 months). Al-Hazmi et $\mathrm{al}^{5}$ reported that the success rate of combined trabeculotomytrabeculectomy with MMC in severe cases (IOP $>35 \mathrm{mmHg}$ and corneal diameter $>14.5 \mathrm{~mm}$ ) of congenital glaucoma was $70 \%$ in 1 or 2 years. The current study offered similar results

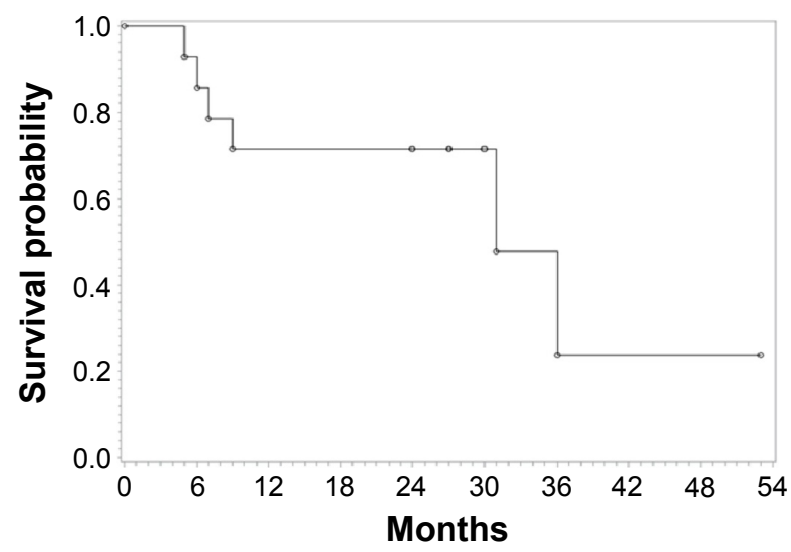

Figure 3 Kaplan-Meier survival analyses showed that the success rates were $85.7 \%$, $71.4 \%$, and $71.4 \%$ at 6,12 , and 18 months, respectively. of AGV implantation (success rate of $71.4 \%$ in 1 year and 18 months) in primary congenital glaucoma with history of previous surgical failure. Some studies found a significantly greater chance of glaucoma control with aqueous shunt implantation compared with trebeculectomy with MMC as a primary procedure. ${ }^{12}$ Mahdy ${ }^{24}$ suggested that the adjunctive use of bevacizumab or MMC could further enhance the chance of AGV implant success. However, others found similar effectiveness between trabeculectomy with MCC and AGV with MMC in pediatric aphakic glaucoma patients. ${ }^{13}$

Currently, there is no consensus as to the preferred surgical algorithm in the treatment of congenital glaucoma after failure of angle surgery or filtration surgery. Glaucoma drainage devices have demonstrated considerable success in congenital glaucoma - 1-year success rates of $92 \%$ by O'Malley et al, ${ }^{23} 63 \%$ by Ou et al, ${ }^{11}$ and 14 out of 17 eyes ( $82 \%$, tube malposition not regarded as failure of surgery) by Djodeyre et al. ${ }^{25} \mathrm{AGV}$ seems to be effective in controlling IOP in refractory pediatric glaucoma when other surgical methods have failed, ${ }^{25,26}$ but there appears to be a higher risk of failure in eyes with congenital glaucoma compared with other diagnoses. ${ }^{10,25}$ The lack of consensus reflects the often small sample size, variable duration of follow-up, and heterogeneity of the patient population in various studies. To the best of our knowledge, the current study is the first to focus exclusively on primary congenital glaucoma that is unresponsive to previous surgical intervention. Should the first AGV implant fail, a second AGV implant may demonstrate an even higher success rate in 5 years. ${ }^{11}$ 
Besides transient shallow anterior chamber and tube malposition, the current study demonstrates a relatively high incidence of severe surgical complication, possibly due to the extreme buphthalmos in this group. ${ }^{27}$ Erosion or exposure of the tube has been shown to be more common in children than in adults, with an incidence of $4.8 \%-33 \%,{ }^{10,11,18,24,27-29}$ especially in buphthalmic eyes. Two eyes undergoing AGV implantation suffered tube extrusion in a group of six extremely buphthalmic eyes. ${ }^{18}$ The long duration of disease and high IOP may affect scleral thickness and rigidity, which may in turn negatively impact implant stability and durability. ${ }^{18}$ In addition, the use of MMC in previous filtration operations may slow healing of conjunctival tissues. ${ }^{24}$ Although donor scleral patches can be used to cover the tube, they cannot completely eliminate the risk of tube exposure. ${ }^{27}$ Tube erosion increases the risk of intraocular infection, ${ }^{27}$ as was seen in the current study.

Suprachoroidal hemorrhage is rare, but it leads to devastating consequences. DSCH can occur hours to months after surgery, either spontaneously or associated with trauma. It manifests as sudden loss of vision, pain, shallow anterior chamber, and high IOP. DSCH appears to be more common after glaucoma drainage device implantation than after trabeculectomy, ${ }^{30-32}$ and may be associated with the use of intraoperative $\mathrm{MMC}$ during $\mathrm{AGV}$ implantation in pediatric glaucoma. ${ }^{31}$ Other risk factors included low postoperative IOP, prior intraocular surgery, and aphakia. ${ }^{32}$ In current study, one patient suffered DSCH 7 months after AGV implant because of trauma. In this case, other potential risk factors were the extreme buphthalmos (AL, $29.21 \mathrm{~mm}, \mathrm{HCD}$, $16 \mathrm{~mm}$ ) with thin sclera and previous filtration surgery.

In previous studies of $\mathrm{AGV}$ implantation in pediatric glaucoma, Englert et $\mathrm{al}^{26}$ and Al-Mobarak et a ${ }^{27}$ reported $3.7 \%$ and $7 \%$ postoperative incidences of retinal detachment, respectively. Choroidal detachment was documented in 17\% of cases by Djodeyre et al. ${ }^{25}$ In the current study, one eye with infantile glaucoma (AL, $29.26 \mathrm{~mm}, \mathrm{HCD}, 15.5 \mathrm{~mm}$ ) had anterior chamber shallowing on the first day after operation. Though the anterior chamber deepened 5 days later, choroidal detachment was noted and later progressed to persistent serous retinal detachment in spite of active medical treatment. Eyes with long-lasting IOP elevation or severe buphthalmos are especially susceptible to developing hypotony-related choroidal or retinal detachment after glaucoma surgery. ${ }^{27}$

There are several limitations to the current study, including a small sample size, its retrospective nature, and the relatively short follow-up time. It also reflects the experience of only one surgeon treating patients of only Chinese descent with primary congenital glaucoma with previous surgical failure. Djodeyre et $\mathrm{al}^{25}$ showed that the surgeon's experience is highly correlated with success of AGV implantation. Therefore, the results of this study may not be applicable elsewhere. Nevertheless, it does suggest that AGV implantation remains a viable option for patients with advanced primary congenital glaucoma, despite a high incidence of severe surgical complications.

\section{Acknowledgment}

The study was supported by Grant 10ykpy26 from the Fundamental Research Funds for the Central Universities (People's Republic of China).

\section{Disclosure}

None of the author has a financial conflict of interest in the subject matter in the manuscript. The authors do not have any commercial or proprietary interest in the product or company mentioned in the manuscript.

\section{References}

1. Liu B, Huang W, He M, Zheng Y. An investigation on the causes of blindness and low vision of students in blind school in Guangzhou. Yan Ke Хие Bao. 2007;23(2):117-120.

2. Aponte EP, Diehl N, Mohney BG. Medical and surgical outcomes in childhood glaucoma: a population-based study. J AAPOS. 2011; 15(3):263-267.

3. Cai Y, Li MY, Shen YY, Liu LY. Long-term effect of trabeculotomy on primary congenital glaucoma. Zhonghua Yan Ke Za Zhi. 2004; 40(11):733-736.

4. McPherson SD Jr, Berry DP. Goniotomy vs external trabeculotomy for developmental glaucoma. Am J Ophthalmol. 1983;95(4):427-431.

5. Al-Hazmi A, Awad A, Zwaan J, et al. Correlation between surgical success rate and severity of congenital glaucoma. Br J Ophthalmol. 2005; 89(4):449-453

6. Lawrence SD, Netland PA. Trabeculectomy versus combined trabeculotomy-trabeculectomy in pediatric glaucoma. J Pediatr Ophthalmol Strabismus. 2012;49(6):359-365.

7. Dietlein TS, Jacobi PC, Krieglstein GK. Prognosis of primary ab externo surgery for primary congenital glaucoma. Br J Ophthalmol. 1999; 83(3):317-322

8. Low S, Hamada S, Nischal KK. Antimetabolite and releasable suture augmented filtration surgery in refractory pediatric glaucomas. J AAPOS. 2008;12(2):166-172.

9. Sidoti PA, Belmonte SJ, Liebmann JM, Ritch R. Trabeculectomy with mitomycin-C in the treatment of pediatric glaucomas. Ophthalmology. 2000;107(3):422-429.

10. Coleman AL, Smyth RJ, Wilson MR, Tam M. Initial clinical experience with the Ahmed glaucoma valve implant in pediatric patients. Arch Ophthalmol. 1997;115(2):186-191.

11. Ou Y, Yu F, Law SK, Coleman AL, Caprioli J. Outcomes of Ahmed glaucoma valve implantation in children with primary congenital glaucoma. Arch Ophthalmol. 2009;127(11):1436-1441.

12. Beck AD, Freedman S, Kammer J, Jin J. Aqueous shunt devices compared with trabeculectomy with mitomycin-C for children in the first two years of life. Am J Ophthalmol. 2003;136(6):994-1000.

13. Pakravan M, Homayoon N, Shahin Y, Ali Reza BR. Trabeculectomy with mitomycin $\mathrm{C}$ versus Ahmed glaucoma implant with mitomycin $\mathrm{C}$ for treatment of pediatric aphakic glaucoma. J Glaucoma. 2007; 16(7):631-636 
14. Kiskis AA, Markowitz SN, Morin JD. Corneal diameter and axial length in congenital glaucoma. Can J Ophthalmol. 1985;20(3):93-97.

15. Sampaolesi R, Caruso R. Ocular echometry in the diagnosis of congenital glaucoma. Arch Ophthalmol. 1982;100(4):574-577.

16. Law SK, Bui D, Caprioli J. Serial axial length measurements in congenital glaucoma. Am J Ophthalmol. 2001;132(6):926-928.

17. Alanazi FF, Song JC, Mousa A, et al. Primary and secondary congenital glaucoma: baseline features from a registry at King Khaled Eye Specialist Hospital, Riyadh, Saudi Arabia. Am J Ophthalmol. 2013;155(5):882-889.

18. Ben-Zion I, Tomkins O, Moore DB, Helveston EM. Surgical results in the management of advanced primary congenital glaucoma in a rural pediatric population. Ophthalmology. 2011;118(2):231-235.

19. Alsheikheh A, Klink J, Klink T, Steffen H, Grehn F. Long-term results of surgery in childhood glaucoma. Graefes Arch Clin Exp Ophthalmol. 2007;245(2):195-203.

20. Essuman VA, Braimah IZ, Ndanu TA, Ntim-Amponsah CT. Combined trabeculotomy and trabeculectomy: outcome for primary congenital glaucoma in a West African population. Eye (Lond). 2011; 25(1):77-83.

21. Zhang X, Du S, Fan Q, Peng S, Yu M, Ge J. Long-term surgical outcomes of primary congenital glaucoma in China. Clinics (Sao Paulo). 2009;64(6):543-551.

22. Tamcelik N, Ozkiris A. Long-term results of viscotrabeculotomy in congenital glaucoma: comparison to classical trabeculotomy. $\mathrm{Br}$ J Ophthalmol. 2008;92(1):36-39.

23. O’Malley Schotthoefer E, Yanovitch TL, Freedman SF. Aqueous drainage device surgery in refractory pediatric glaucomas: I. Long-term outcomes. J AAPOS. 2008;12(1):33-39.
24. Mahdy RA. Adjunctive use of bevacizumab versus mitomycin $\mathrm{C}$ with Ahmed valve implantation in treatment of pediatric glaucoma. J Glaucoma. 2011;20(7):458-463.

25. Djodeyre MR, Peralta Calvo J, Abelairas Gomez J. Clinical evaluation and risk factors of time to failure of Ahmed glaucoma valve implant in pediatric patients. Ophthalmology. 2001;108(3):614-620.

26. Englert JA, Freedman SF, Cox TA. The Ahmed valve in refractory pediatric glaucoma. Am J Ophthalmol. 1999;127(1):34-42.

27. Al-Mobarak F, Khan AO. Complications and 2-year valve survival following Ahmed valve implantation during the first 2 years of life. Br J Ophthalmol. 2009;93(6):795-798.

28. Hill R, Ohanesian R, Voskanyan L, Malayan A. The Armenian Eye Care Project: surgical outcomes of complicated paediatric glaucoma. Br J Ophthalmol. 2003;87(6):673-676.

29. Morad Y, Donaldson CE, Kim YM, et al. The Ahmed drainage implant in the treatment of pediatric glaucoma. Am J Ophthalmol. 2003; 135(6):821-829.

30. Tuli SS, WuDunn D, Ciulla TA, Cantor LB. Delayed suprachoroidal hemorrhage after glaucoma filtration procedures. Ophthalmology. 2001;108(10):1808-1811.

31. Ghadhfan FE, Khan AO. Delayed suprachoroidal hemorrhage after pediatric glaucoma surgery. J AAPOS. 2009;13(3):283-286.

32. Jeganathan VS, Ghosh S, Ruddle JB, Gupta V, Coote MA, Crowston JG Risk factors for delayed suprachoroidal haemorrhage following glaucoma surgery. Br J Ophthalmol. 2008;92(10):1393-1396.
Clinical Ophthalmology

\section{Publish your work in this journal}

Clinical Ophthalmology is an international, peer-reviewed journa covering all subspecialties within ophthalmology. Key topics include: Optometry; Visual science; Pharmacology and drug therapy in eye diseases; Basic Sciences; Primary and Secondary eye care; Patient Safety and Quality of Care Improvements. This journal is indexed on

Submit your manuscript here: http://www.dovepress.com/clinical-ophthalmology-journal

\section{Dovepress}

PubMed Central and CAS, and is the official journal of The Society of Clinical Ophthalmology (SCO). The manuscript management system is completely online and includes a very quick and fair peer-review system, which is all easy to use. Visit http://www.dovepress.com/ testimonials.php to read real quotes from published authors. 